\title{
The Enlightenment of the American Medical Physicists Talent Training Mechanism to the New Engineering in Local Universities
}

\author{
Xueyan ZHOU* \\ College of Engineering \\ Harbin University College of Engineering \\ Harbin, China \\ xueyanzhou@uchicago.edu
}

\author{
Qiubin LUO, Boling SUN, Lan ZHENG \\ College of Engineering \\ Harbin University College of Engineering \\ Harbin, China
}

\begin{abstract}
Local application-oriented colleges and universities are an effective boost to local economic development. New engineering, especially interdisciplinary disciplines, have brought new directions and opportunities for the transformation and development of local undergraduate colleges and universities. Taking the University of Chicago Medicine as an example, this paper analyzed the access conditions, certification status, curriculum construction and faculty status of graduate students in medical physics in North America, and gave suggestions on the traditional professional personnel training new direction in combination with China's current situation. This research can be used as a reference for traditional professional new engineering reform.
\end{abstract}

Keywords-Medical physicists; Talent Cultivation; Accreditation; Curriculum construction

\section{INTRODUCTION}

Physics is an important basic science. In recent years, the physics application combined with the practical application is also developing rapidly. Medical physics is an interdisciplinary subject that combines physics with medical practice. By applying the principles and methods of physics to medicine, the prevention, diagnosis, treatment and health care of human diseases can be realized. For local colleges and universities, the high-level theoretical research of traditional physics cannot be carried out, and the employment scope of students is relatively narrow. Under this background, the development of applied physics has become a trend. Medical physicists are compound talents who have a good command of physics and medical knowledge and technology. They are mainly engaged in the introduction, acceptance and maintenance of tumor radiotherapy equipment, the formulation, review and confirmation of treatment schemes, network maintenance, radiation protection and safety guarantee, and the training and research and development of new technologies [1, 2].Developed countries in Europe and America attach great importance to the talent training of this discipline. Since the 1950s, the talent training of medical physics started in the United States, Australia and other countries and regions. At the same time, in order to better serve the medical industry, many national and international organizations in North America, Europe and other regions have been committed to training

Fund Assistance: It is supported by Heilongjiang Province Educational Scientific Planning Key Project (GBB1318063). excellent medical physicists [3,4].At present, the training, assessment and employment system of medical physics has not been established in China. In this context, this paper analyzes the training, recruitment, faculty and assessment methods of medical physics talents in radiology department of the university of Chicago, in order to provide support for the development of traditional professional new engineering.

\section{QUALITY ASSURANCE OF AMERICAN MEDICAL PHYSICS EDUCATION SYSTEM}

\section{A. CAMPEP and its mission}

The nonprofit organization CAMPEP is independent of its sponsoring organizations, and its goal is to review and improve the educational programs in medical physics. The main mission of CAMPEP is to improve consistent quality education of medical physicists for meeting the high standards which is established by CAMPEP and its sponsoring organizations.

Accreditation is a peer review process, which always is voluntary and non-governmental. The goal is to ensure that a project or organization meets the minimum required standards. CAMPEP provides professional accreditation for medical physics education programs, such as degree award programs, clinical internships, continuing education and short-term courses. In some cases, CAMPEP accreditation may allow students to receive funds in the form of scholarships, loans or grants.

A self-assessment report should be submitted in the degree award certification and clinical training program to prove that it meets the requirements. After reviewing the report, the team conducted on-site project visits to validate the assessment results. If successful, the accreditation period is 5 years. Renewal requires submitting updated self-assessment report.

Usually, the survey team is composed of senior medical physicists who have experience in clinical practice and educational projects. Generally, it also includes a doctor. Medical physics is the application of physics and related sciences in medical practice. More information on medical physics can be obtained from 5 sponsors in CAMPEP. 


\section{B. The operation mechanism of CAMPEP}

CAMPEP is supported by five organizations, each of which plays an important role in the development of the medical physics profession.

- AAPM founded in 1958, which is a scientific and professional organization. It is composed of more than 8000 scientists.

- $\quad$ The American College of Radiology (ABR), founded in 1924, is at the forefront of the development of Radiology and is responsible for the testing of individual competence and certification of medical physicists. By empowering its members to advance the practice of radiotherapy, ABR serves patients and society scientifically and professionally.

- Founded in 1958, the American Society for Radiation Oncology is the world's premier Radiation Oncology organization. It has more than 10,000 members, including doctors, nurses, biologists, physicists, radiotherapy technicians and other healthcare professionals engaged in radiotherapy.

- Canadian Medical Physicists Organization COMP is the practice in Canada Medical Physicists major professional organizations.

- $\quad$ The Radiological Society of North America. The North American Radiological Society (RSNA) is a non-profit organization with more than 54,000 members in 136 countries. RSNA provides high-quality educational resources, including continuing education credits for physician certification, holding the world's largest radiology conference, and publishing two peerreviewed high-level journals: radiology and radiography.

\section{Status of CAMPEP certification}

According to the data updated by CAMPEP on January 11, 2019, a total of 54 universities in the world have passed the medical physics postgraduate education certification, including 41 universities in the United States, 11 universities in Canada, 1 university in South Korea and 1 university in Ireland [5, 6].According to statistics, the university of Wisconsin and Wayne state university in the United States were the first to pass in 1988. The two new universities that passed in 2018 are Creighton University and Thomas Jefferson University in the United States. It is difficult to pass the certification, and the global distribution of the number of accredited universities each year is shown in Fig. 1.

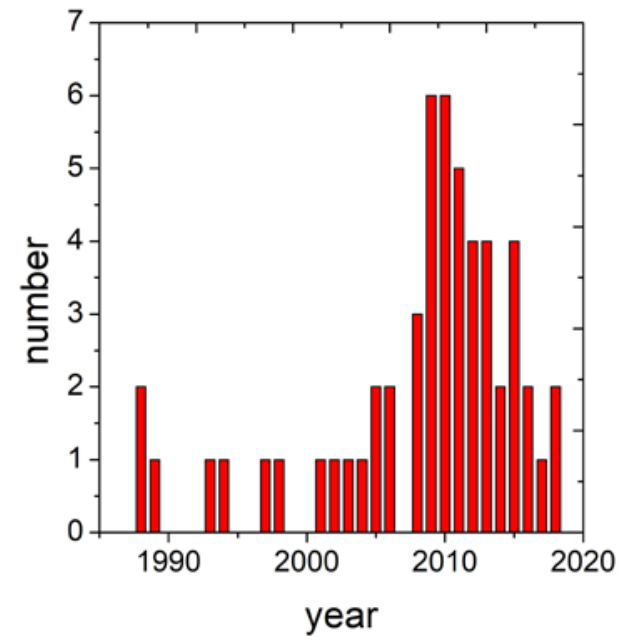

Fig. 1 University Distribution through Medical Physics Graduate Education Accreditation Every Year

\section{UNIVERSITY OF CHICAGO GRADUATE TRAINING IN MEDICAL PHYSICS}

\section{A. Faculty}

Accredited Postgraduate Courses are offered by the Medical Physics Committee of the University of Chicago. Medical physics applies the principles of physical science to biomedical problems. Medical physicists have a wide range of activities, ranging from the study of basic biomedical processes to the diagnosis and treatment of diseases, so their training must be extensive. In order to participate effectively in this interdisciplinary specialty, medical physicists must be fully competent in physics and mathematics related to imaging physics and radiation physics, understand biological principles, and be able to communicate with doctors.

The Medical Physics Committee provides projects to provide aspiring medical physicists with the knowledge they need for their future careers. The project usually focuses on research that provides career preparation for doctoral degrees in academia, industry and clinical support. The University of Chicago Medical Physics Project is internationally recognized for its outstanding research. Now, many investigators are leaders in their respective professions. At the same time, the project is located in the University Medical Center, which enables a strong interaction between clinical staff and researchers. Teachers with major interest in diagnostic imaging work in the radiology department, while those with major interest in Radiotherapy Physics work in the Radiology and Cell Oncology department.

At present, the graduate program of medical physics is composed of two administrators and 23 teachers, among whom 14 are in the department of radiology and 9 are in the department of radiology and cell oncology, including 6 professors, 11 associate professors and 6 assistant professors. These teachers also serve on the medical physics committee. Most of the research projects involve the 
cooperation between basic scientists and clinicians. The average tenure is 16.3 years.

\section{B. Requirements for admission to the doctoral program in medical physics}

At the macro level, training for medical physicists must be extensive. To successfully participate in this interdisciplinary program, students must have a complete grasp of the physical and mathematical sciences, must understand biological and physiological systems, and must be able to understand and communicate with a professional physician. Typically, candidates for a graduate degree in medical physics must have a bachelor's degree in physics, a thorough understanding of basic physical phenomena, and sufficient knowledge of biological systems to apply physical concepts and principles to practical problems and be able to communicate ideas to others.

The University of Chicago, with its outstanding departments of physics, mathematics and biological sciences and a medical school that values academic research, provides a particularly favorable environment for students seeking this training. Doctoral candidates may choose to conduct research in the department of radiology, the department of radiation and cellular oncology, or any other department where physical phenomena are directly applied to medicine, including audiology, cardiology, neurology, and ophthalmology. Medical physics postgraduate doctor admission needs to pass the written test and interview, comprehensive investigation students physics, biology and other basic knowledge, candidates need to have a university level biology course basis.

\section{Students}

Taking the medical physics research and development program in the department of radiology at the University of Chicago as an example, Table I show 10 years of student applications and graduation.

Please note that during the period covered by the above statistics, $100 \%$ of the graduates had applied for clinical posts or were in the process of residency.

\section{CURRICULUM CONSTRUCTION}

Usually, the doctoral degree requires 5-6 years of work. On one hand, they should complete the course requirements, on the other hand, graduate students must complete papers approved by the committee and must pass the defense. There are four semesters in the university of Chicago academic year, so fulltime students should take three courses each quarter.

TABLE I. MEDICAL PHYSICS Ph.D. STUdENTS AT THE UNIVERSITY OF CHICAGO

\begin{tabular}{|c|c|c|c|c|c|c|c|c|c|c|c|}
\hline $\begin{array}{c}\text { Calendar } \\
\text { Year }\end{array}$ & $\mathbf{0 7}$ & $\mathbf{0 8}$ & $\mathbf{0 9}$ & $\mathbf{1 0}$ & $\mathbf{1 1}$ & $\mathbf{1 2}$ & $\mathbf{1 3}$ & $\mathbf{1 4}$ & $\mathbf{1 5}$ & $\mathbf{1 6}$ & $\mathbf{1 7}$ \\
\hline $\begin{array}{c}\text { Applicants } \\
\text { Applied }\end{array}$ & 29 & 40 & 39 & 42 & 30 & 42 & 39 & 38 & 43 & 54 & 57 \\
\hline $\begin{array}{c}\text { Applicants } \\
\text { Accepted }\end{array}$ & 9 & 6 & 6 & 10 & 4 & 8 & 6 & 8 & 7 & 8 & 8 \\
\hline $\begin{array}{c}\text { Applicants } \\
\text { Enrolled }\end{array}$ & 4 & 4 & 4 & 4 & 4 & 3 & 3 & 4 & 3 & 4 & 4 \\
\hline $\begin{array}{c}\text { Students } \\
\text { Graduated }\end{array}$ & 4 & 1 & 1 & 9 & 3 & 5 & 3 & 4 & 5 & 3 & 3 \\
\hline
\end{tabular}

\begin{tabular}{|c|c|c|c|c|c|c|c|c|c|c|c|}
\hline \multicolumn{10}{|c|}{ Cont. to TABLE I. } \\
\hline \multicolumn{10}{|c|}{ Post-graduation Position/Activity } \\
\hline Residencies* & 2 & 0 & 0 & 1 & 1 & 2 & 1 & 3 & 3 & 0 & 1 \\
\hline $\begin{array}{c}\text { Advanced } \\
\text { Degree }\end{array}$ & 0 & 0 & 0 & 0 & 1 & 0 & 0 & 0 & 0 & 0 & 0 \\
\hline Industry & 1 & 0 & 0 & 2 & 0 & 1 & 1 & 1 & 1 & 0 & 0 \\
\hline $\begin{array}{c}\text { Clinical } \\
\text { Positions* }\end{array}$ & 0 & 0 & 0 & 2 & 0 & 0 & 0 & 0 & 0 & 0 & 0 \\
\hline $\begin{array}{c}\text { Academic } \\
\text { Positions }\end{array}$ & 1 & 1 & 1 & 4 & 1 & 2 & 2 & 0 & 1 & 3 & 1 \\
\hline $\begin{array}{c}\text { Other } \\
\text { Activities }\end{array}$ & 0 & 0 & 0 & 0 & 0 & 0 & 0 & 0 & 0 & 0 & 1 \\
\hline
\end{tabular}

Graduate students in medical physics are enrolled in the fall semester, and the learning process continues throughout the academic year. The University of Chicago medical physics board provides guidance to PhD students in medical physics and students can customize and complete all required courses within two academic years, as shown in Table II. At the same time, the missing precursors will be provided by departments due to the different entry backgrounds. All students need to have a university-level biology course foundation. If students lack this part of content and need to complete the make-up course in the university, the credits obtained from this part of learning will not be included in the degree grade point average.

Course requirements for Ph.D. students in the Graduate Program in Medical Physics include passage of at least 13 quarter courses with a "B" average and with no grade lower than "C". These must include the twelve (12) basic required courses and one (1) elective course. The elective course must be approved by the student's GPMP advisor. First year students are expected to complete 4 research rotations during their first 4 quarters, enabling them to be registered as a full-time student and giving them exposure to different topics in medical physics. Students entering the program with a Master's degree will have the one elective course waived (with credit).

Every September, each student who completes the first full academic year will take a qualified comprehensive examination, which includes the materials in the course and basic undergraduate physics so far. The aim of examination is to measure the knowledge of general medical physics for each student. Usually, a four-hour "closed-book" written test, a twoday "open-book" written test and an one-hour oral test for the Department of Medical Physics will be conducted.

TABLE II. Medical physics Ph.D. Suggested Course SEQUENCE AT THE UNIVERSITY OF CHICAGO

\begin{tabular}{|c|l|l|}
\hline Quarter & \multicolumn{1}{|c|}{ Year 1 } & \multicolumn{1}{c|}{ Year 2 } \\
\hline \multirow{5}{*}{ Autumn } & $\begin{array}{l}\text { Interactions of Ionizing } \\
\text { Radiation with Matter }\end{array}$ & $\begin{array}{l}\text { Anatomical Structure of the } \\
\text { Body }\end{array}$ \\
\cline { 2 - 3 } & $\begin{array}{l}\text { Mathematics for Medical } \\
\text { Physicists }\end{array}$ & $\begin{array}{l}\text { Statistics in the Natural } \\
\text { Sciences }\end{array}$ \\
\cline { 2 - 3 } & Research rotation & Research course \\
\hline \multirow{5}{*}{ Winter } & Physics of Radiation Therapy & Cancer \& Radiation Biology \\
\cline { 2 - 3 } & $\begin{array}{l}\text { Practicum in Physics of } \\
\text { Radiation Therapy }\end{array}$ & $\begin{array}{l}\text { Elective course or research } \\
\text { or teaching assistantship }\end{array}$ \\
\cline { 2 - 3 } & Research rotation & Research \\
\hline \multirow{5}{*}{ Spring } & Physics of Medical Imaging I & \\
\cline { 2 - 3 } & $\begin{array}{l}\text { Practicum in the Physics of } \\
\text { Medical Imaging I }\end{array}$ & $\begin{array}{l}\text { Elective course or research } \\
\text { or teaching assistantship }\end{array}$ \\
\cline { 2 - 3 } & Research rotation & Research \\
\cline { 2 - 3 } & $\begin{array}{l}\text { Biological Science Division } \\
\text { Bioethics }\end{array}$ & Health Physics \\
\hline
\end{tabular}




\begin{tabular}{|l|l|l|}
\hline \multicolumn{3}{|c|}{ Cont. to TABLE II. } \\
\hline \multirow{4}{*}{ Summer } & Physics of Medical Imaging II & \\
\cline { 2 - 3 } & $\begin{array}{l}\text { Practicum in the Physics of } \\
\text { Medical Imaging II }\end{array}$ & Elective course or research \\
\cline { 2 - 3 } & Research rotation & Research \\
\hline
\end{tabular}

The Qualification Comprehensive Examination (QCE) aims at assessing students' ability to successfully fulfill doctoral requirements. Examination results are directly related to students' next learning plan. They will pass the Ph.D. level; pass the Master's degree and fail by the plurality vote of faculty (The students will quit the course)

\section{CONCLUSION}

The serious shortage of medical physics professionals in China greatly restricts the cooperation between medical physicists and clinicians and the development and use of highend medical equipment. Medical physics professionals have three aspects of training objectives: (1) Medical physicists; (2) teaching and research talents in medical physics; (3) high-end medical equipment industry research and development personnel. In these three aspects of the talent market, China should have tens of thousands of people's talent demand. It can be seen that for traditional engineering majors in local colleges and universities, broadening professional development ideas and serving local economic development, especially in medical and health and other livelihood fields, will largely promote employment. To be specific, the following Suggestions are given based on the deficiencies in the cultivation of new engineering niche professionals:

(1) Most of local colleges and universities have physics, mathematics, biology, engineering, electronic technology, computer engineering, such as traditional, the graduates of these disciplines can be by train to become medical physicists, therefore, the need to promote this kind of professional application class, there are medical university interdisciplinary cooperation, there is no medical university should actively docking with the hospital and cooperation in running schools.

(2) To increase the exchange of talents with foreign countries, institutions that have already carried out personnel training in this field should send teachers to Europe, America and other developed countries in a planned way to learn advanced experience. Take the radiotherapy department of the university of Chicago school of medicine as an example, The main staff includes 15 radiologists and 7 medical physicists (all with doctoral degrees).The learning content mainly includes how to establish a research team with doctors, the appointment and assessment of medical physicists, the sharing of teachers and certification experience.

(3) Strengthen exchanges with other universities. Medical physics talents cannot be cultivated without medical background, which is difficult for universities without medical schools. On the one hand, we should encourage the exchange with other colleges and universities, such as the orientation training of students, the exchange of visits of teachers and the practice in hospitals. On the other hand, broaden the thinking, from the use of equipment, maintenance, data analysis and other aspects of the gradual penetration of medical physics direction.

To sum up, local colleges and universities should be encouraged to transform traditional majors into new engineering niche majors, and meanwhile develop medical physics, architectural electricity and other professional directions to serve the local economy.

\section{ACKNOWLEDGMENT}

It is supported by Heilongjiang Province Educational Scientific Planning Key Project (GBB1318063). One of the authors (XY) wishes to acknowledge the support of China Scholarship Council (CSC) for her scholarship to study abroad.

\section{REFERENCES}

[1] CAI Xue-zhu, Du Yi-ping. American Medical Physicist's Cultivation System [J]. Chinese Journal of Medical Physics, 2013, 30 (02):40704075. (In Chinese)

[2] WANG Xiao-yan, JI Xu-cai, WANG Peng-cheng, XIE Jin-dong. The Research and Considering of Medical Physics Characteristic Specialty [J]. Chinese Journal of Medical Physics, 2014, 31 (04):5095-5100. (In Chinese)

[3] WANG Xiao-yan, WANG Peng-cheng, SONG li, XIE Jin-dong, LIU Lin-xiang. Building Reasonable Practical Teaching System and Training High Quality Medical Physicist [J]. Chinese Journal of Medical Physics, 2013, 30 (06):4589-4592. (In Chinese)

[4] WANG Zhi-yuan, PENG Jie, LV Qing-wen, XU Qi-fei, FENG Yan-qiu, CHEN Wu-fan. Some Conceptions of Specialty Construction for Medical Physics of China [J]. Chinese Journal of Medical Physics, 2013, 30 (02):4070-4075. (In Chinese)

[5] Professional Doctorate in Medical Physics (DMP) Degree Programs. Commission on Accreditation of Medical physics Education Programs. http://www.campep.org/.

[6] Department of Radiology Graduate Program in Medical Physics University of Chicago. https://radiology.uchicago.edu/page/graduateprogram-medical-physics. 